\title{
FOUCAULT, DELEUZE E A MÁQUINA ESCOLAR: \\ A ESCOLA COMO DISPOSITIVO DE PODER E A PRODUÇÃO DE CORPOS DÓCEIS
}

\author{
Bruno Abílio Galvão ${ }^{1}$
}

RESUMO: Os conceitos de "máquina abstrata" e "agenciamento" do filósofo Gilles Deleuze, elaborados a partir de seus estudos sobre Michel Foucault, nos permitem compreender as relações de poder na escola. O espaço escolar, caracterizado como um agenciamento, ao atualizar uma máquina abstrata, estabelece uma forma de relação entre os indivíduos fazendo funcionar uma maquinaria complexa, produzindo certo tipo de indivíduo, cujos objetivos, traçados desde a revolução industrial, perpetuam-se até hoje. Portanto, o objetivo de nosso trabalho é compreender o papel da escola na sociedade por meio do pensamento de Gilles Deleuze e Michel Foucault acerca do poder. O método utilizado é de pesquisa bibliografia referente a tais pensadores e também sobre a escola. Esse tema se torna relevante pelo fato de nos proporcionar uma postura crítica em relação, não só ao papel da escola, mas também à postura dos integrantes desse espaço.

PALAVRAS-CHAVE: Agenciamento; Corpos Dóceis; Escola; Máquina; Poder. 


\begin{abstract}
The concepts of "abstract machine" and "agency" of the philosopher Gilles Deleuze, developed from his studies of Michel Foucault, allow us to understand the power relations in school. The school environment, characterized as an agency, to upgrade an abstract machine, establishes a form of relationship between individuals by operating a complex machine, producing certain type of individual, whose goals, strokes, since the industrial revolution, perpetuating up to date. Therefore, the aim of our work is to understand the school's role in society through the thought of Gilles Deleuze and Michel Foucault's power. The method used is bibliographic research on such thinkers as well as research on the school. This issue becomes relevant because give us a critical stance in relation not only to the role of the school, but also the attitude of the members of that space.
\end{abstract}

KEYWORDS: Agency; Docile Bodies; School; Machine; Power. 


\section{INTRODUÇÃO}

Deleuze, ao pensar a questão do poder e do saber em Foucault, o faz utilizando os conceitos de "máquina abstrata" e "agenciamento". A máquina abstrata corresponde, segundo ele, ao conceito de "diagrama" de Foucault, que é, além de um conceito que se refere às formações discursivas, um mapa das relações de poder exercidas em determinados espaços. Por sua vez, o "agenciamento", correspondendo ao conceito de "dispositivo", se refere ao espaço físico em que as relações de poder são efetuadas. A forma de exercício de poder nos agenciamentos é configurada segundo a "máquina abstrata”, o mapa, que determina posições diagramáticas em um espaço.

A partir desses conceitos classificamos a escola como um "agenciamento" que atualiza uma "máquina abstrata" formada, em parte, pelos discursos referentes à criança e à necessidade de educá-la de acordo com certas finalidades sociais. A escola, ao atualizar uma máquina abstrata, proporciona a formação de determinado tipo de sujeito por meio de um modo específico de relações de poder, caracterizado por Foucault como "poder disciplinar". Porém, não nos deteremos na análise dos mecanismos disciplinares, mas sim seguiremos no sentido de analisar a constituição da escola segundo os conceitos deleuzianos de "máquina abstrata" e "agenciamento" e mostraremos, também, segundo quais objetivos o poder disciplinar exercido participa de um ideal político, ocupando uma função social.

Trabalharemos então, uma vez que há a interseção do pensamento desses dois pensadores, com Foucault e Deleuze 
e com alguns autores complementares sobre o assunto, ou seja, nosso método se restringe ao estudo de bibliografias sobre o tema. A relevância desse assunto se afirma no fato de proporcionar o questionamento sobre as relações estabelecidas entre os diversos indivíduos integrantes da escola e o papel dela na sociedade.

\section{DELEUZE E OS CONCEITOS DE "MÁQUINA ABSTRATA"E "AGENCIAMENTO"}

Segundo Nabais (2009), os conceitos de "máquina abstrata" e "agenciamento" foram elaborados por Deleuze a partir de seus estudos sobre as relações de poder em Foucault ${ }^{2}$. Tais estudos culminaram em uma obra que leva o nome do mesmo, sendo Foucault considerado por Deleuze (2005, p. 33) como "um novo cartógrafo". Mas, qual o sentido de um filósofo ser classificado como "cartógrafo"? A cartografia trata de um estudo científico pautado na produção de mapas, uma vez que, para se produzir um mapa, é necessário haver um espaço físico e concreto como referência. Portanto, Deleuze, ao caracterizar Foucault como cartógrafo, o faz devido ao fato de ele, ao analisar um espaço, ser capaz de mapear algo.

Um mapa pode ser composto por diversos elementos de acordo com o objeto ao qual se planeja mapear. Há mapas específicos para cada tipo de necessidade. Qual é, então, o objeto que Foucault, ao analisar determinados espaços, vem a mapear? Deleuze afirma que Vigiar e Punir (2007) é uma obra que marca, no pensamento de Foucault, a transição 260 
de uma analítica do saber para uma "cartografia do poder". Por conseguinte, Foucault é um cartógrafo que, por meio de suas análises dos diversos espaços, traça um "diagrama" do poder. Traçar um diagrama do poder significa mostrar seu funcionamento independente de qualquer obstáculo, sem outorgá-lo a nenhum uso específico. O diagrama é o mapa, a cartografia é extensiva a todo campo social.

Diremos, então, que o diagrama "é a exposição das relações de forças que constituem o poder" (DELEUZE, 2005, p. 46) em um espaço. Essas relações de forças são sempre "estratégicas, microfísicas, difusas, elas constituem funções puras, formam um campo abstrato" (NABAIS, 2009 , p. 10). O diagrama não aponta o poder enquanto realidade passiva, mas sim suas relações que ocorrem no mais capilar elemento constituinte desse espaço e, também, das estratégias de manipulação de tais relações. O campo traçado é abstrato, mas as relações são concretas e, cada relação, por minúscula que seja, corresponde a uma linha ou vetor traçado nesse campo abstrato em que uma ação ocasiona uma reação, e uma atuação estratégica num determinado espaço ocasiona reações mais abrangentes, como uma engrenagem que, ao girar, movimenta outra, produzindo movimento cujo objetivo final é a produção de um efeito esperado. Observando esse funcionamento do poder por meio do conceito de diagrama, Deleuze concebe esse conjunto de engrenagens do poder como uma máquina e, uma vez que o campo traçado é abstrato, a máquina também é abstrata.

Deleuze pretende, ao buscar elementos para seu conceito de "máquina abstrata" em Vigiar e Punir, mostrar como são 
exercidas as relações de poder (NABAIS, 2009). Então, o diagrama ou máquina abstrata não é uma intelecção pura no sentido platônico, mas sim uma abstração ou saber produzido a partir das relações estratégicas de poder que constituem modelos e, provavelmente, são aplicados em espaços diferentes.

A máquina abstrata é um saber estratégico originado das relações de poder em uma determinada localidade. Ao ser aplicado em outro espaço, este saber estratégico proporciona a configuração de certas formas de relações - técnicas de exercício de poder - de um espaço a outro estruturando novas relações de poder. A esses espaços em que a máquina abstrata é aplicada Deleuze (2005) denomina de "agenciamentos". Se, por um lado, temos a máquina abstrata que corresponde ao diagrama das relações de poder, o agenciamento é onde se efetua o mapeamento das relações de força no plano concreto e também onde as estratégias discursivas são efetuadas. Logo, o campo traçado como mecanismo de poder, contendo todas as suas estratégias e vetores de força, pode ser aplicado em outro espaço cuja função é agenciar e efetuar as relações de poder mapeadas. A máquina abstrata atua, dessa forma, como causa dos agenciamentos, efetuando-se por meio destes simultaneamente. Esse processo se chama "causa imanente", que significa:

[...] causa que se atualiza em seu efeito, que se integra no seu efeito, que se diferencia no seu efeito. Ou melhor, a causa imanente é aquela cujo efeito a atualiza, a integra e diferencia. Por isso nela há correlação, pressuposição 
recíproca entre a causa e o efeito, entre a máquina abstrata e os agenciamentos concretos (é a esses que Foucault reserva mais frequentemente o nome de “dispositivos"). (DELEUZE, 2005, p. 46)

Por consequência, a causa imanente corresponde à atuação de algo abstrato, a máquina ou diagrama, em algo concreto, agenciamento ou dispositivo para Foucault. A máquina ou mapa de relações de poder são efetuados somente no plano concreto, portanto, todos os elementos traçados, os mecanismos abstratos, são atualizados nos agenciamentos que, por sua vez, efetuam visivelmente as relações de poder.

A máquina abstrata é efetuada como causa imanente, sendo ela o mapa ou diagrama transposta num espaço concreto proporcionando relações de poder. Mas, as relações de poder mapeadas no diagrama existem somente, enquanto real, quando atualizadas pelos agenciamentos, o poder não existe em si mesmo, mas possui uma realidade virtual. $\mathrm{O}$ virtual "deve ser definido como uma estrita parte do objeto real - como se o objeto possuísse uma de suas partes no virtual, e aí mergulha-se como uma dimensão objetiva" (DELEUZE apud ZOABICHIVILE, 2007, p. 62). Então o poder integra, enquanto realidade virtual, um objeto real. Mas, como o virtual se relaciona com o real?

"O virtual é a insistência do que não é dado" (ZOABICHIVILE, 2007, p. 62), ou seja, é a insistência e movimentação de uma força que interfere no estado do que está posto como "dado", determinando certa forma de movimento ou redirecionamento do mesmo. O poder, enquanto virtual, 
atua no âmbito das possibilidades, dos acontecimentos possíveis que podem ocorrer no real. É no real que ele se atualiza. O poder é "a propensão para fazer, a disposição para agir" (NABAIS, 2009, p. 11), mas essa propensão e disposição Deleuze não atribui aos agentes, mas sim as estabelecem como "propriedades das máquinas abstratas" (NABAIS, 2009, p. 11). Portanto, as ações são realizadas por um agente, mas o que proporciona agir de determinada forma estabelecendo relações de poder é de propriedade da máquina. A máquina é o efetuador de determinadas formas de relação.

A máquina abstrata atualiza-se nos agenciamentos concretos, mas, a constituição desses agenciamentos não se limita apenas à arquitetura espacial. O espaço, sem os agentes, não funciona, a escola não existe sem que haja alunos e professores e outros elementos humanos, igualmente as fábricas e o exército. Portanto, a atualização da máquina ocorrerá nesses elementos que Deleuze chama de "substâncias qualificadas" (NABAIS, 2009, p. 11). Os agenciamentos não atualizam a máquina apenas pelo fato de suas substâncias qualificadas permanecerem no espaço, há, além disso, "funções finalizadas" (NABAIS, 2009, p. 11) que desencadeiam uma forma de relação de poder. No caso do agenciamento escola, suas substâncias qualificadas possuem uma função finalizada, educar, que desencadeia um regime de poder disciplinar.

Porém, ao atualizarem-se no real, os efeitos da máquina abstrata não são exatos, pois, uma vez que a máquina é um diagrama de múltiplas relações de poder e estas, ao sobrecaírem sobre os agentes dos agenciamentos lhes configurando determinada função finalizada, não há 
garantias de como essas implicações serão efetuadas pelo indivíduo, deixando, ainda, aberta a possibilidade de resistência.

Podemos dizer que uma máquina possui duas realidades, uma abstrata, que contém a tecnologia do poder a ser exercida nas relações em determinados espaços, e outra concreta, que funciona segundo as determinações da primeira atualizando e promovendo os efeitos do poder. A máquina então é um composto de estratégia ou tecnologia, espaço físico e material humano, confluindo para um funcionamento em que cada agente desse espaço atue como uma engrenagem, como peça de uma estrutura maior, cujas atitudes são impulsionadas pelos mecanismos de poder presentes na máquina abstrata, direcionando-as para que um todo se mantenha funcionando, sustentando assim a funcionalidade dos agenciamentos ou dispositivos de poder.

Realizada essa apresentação dos conceitos deleuzianos a partir do pensamento de Michel Foucault, direcionemo-nos então para uma máquina específica, a escola, que funciona como agenciamento atualizador das relações de poder demarcadas por um diagrama pedagógico disciplinar, exercendo uma função como dispositivo de poder. Nossos próximos passos consistem em mostrar o surgimento histórico da máquina escolar, bem como sua função social e política, depois a constituição de um conceito que integra a formação discursiva que compõe a máquina abstrata, o de "criança" que, a partir deste, esses indivíduos passarão a serem vistos como possibilidades específicas (corpos dóceis) se submetidos a um regime disciplinar. 


\section{CONTEXTO DO APARECIMENTO DA MÁQUINA ESCOLAR}

O modelo de máquina escolar presente é o produto da relação entre diversas práticas discursivas (máquinas abstratas) e relações de poder efetuadas em diversos agenciamentos, que configuraram toda a sociedade moderna. A modernidade é marcada por uma série de fenômenos políticos e econômicos, sendo, talvez, o mais significativo, o surgimento das indústrias, que ocasionou várias mudanças na relação homem - trabalho e também na forma com que este passou a ser compreendido segundo a mudança das necessidades de produção. Antes, num período prémoderno, o trabalhador dispunha dos meios de produção e tinha total controle de todos os processos na elaboração de seu produto, do tempo e da maneira em que seria produzido, pois o produto final era fruto de sua arte. Posteriormente, com o advento da indústria, o indivíduo é submetido a executar determinadas funções no processo de produção em uma escala de tempo previamente definida. Esse processo de desenvolvimento industrial também proporcionou o aumento da população urbana, num primeiro momento devido à migração da população rural para os grandes centros em busca de melhores condições de sobrevivência (ENGUITA, 1989) e, posteriormente, com estratégias de controle da população, enquanto aspecto orgânico, visando à preservação da vida, o que Foucault chamará de "biopoder" (FOUCAULT, 2007).

Dessa forma, a modernidade é marcada por um momento em que há a consolidação de novos mecanismos econômicos e, também, por uma crescente população urbana. O que, a 
princípio, são fenômenos que se complementam, pois, com o surgimento das fábricas, há uma demanda por trabalhadores que é sanada com o aumento da população. O homem passa a ser visto como peça adaptável aos mecanismos de produção, pois a indústria necessita de componentes humanos em suas estruturas para funcionar. O crescimento demográfico urbano demanda, independente de empregada em postos de trabalho ou não, a necessidade de se criar mecanismos de controle sobre os indivíduos, pois, com o crescimento demasiado da população, precisava-se "civilizar" as massas e cuidar para que suas "impurezas" 3 não se propagassem para toda a sociedade, para isso a necessidade de um biopoder. O biopoder é uma tecnologia utilizada com o intuito de preservar a vida num sentido em que permite, ao se esquadrinhar e individualizar as populações, produzir conhecimentos referentes aos processos biológicos, por exemplo, a quantidade de mortes e nascimentos que ocorrem, informações sobre a saúde da população, etc. Mediante tal saber produzido, estabelecemse formas de intervir e controlar tais movimentos biológicos da população. Esta tecnologia de poder é aplicada segundo a compreensão do corpo enquanto espécie, objetivando sua perpetuação sadia na medida em que proporciona o controle sobre determinada população.

Diante dessas mudanças sociais, o Estado desenvolve com o objetivo de controle populacional num sentido de biopolítica e também de força de produção, o que Foucault chama de governamentalidade (FOUCAULT, 2010). A governamentalidade é uma tecnologia que, diante de todo o 
corpo social, delimita o espaço de cada indivíduo tornando possível governar a vida de cada um, direcionando-a para um fim específico e ditando normas de conduta. Essa arte de governar surge pela associação entre "o jogo da cidade" e o "jogo do pastor" (BUJES, 2002, p. 76).

O jogo do pastor constitui-se num tipo de relação pautada no cuidado de um indivíduo, o pastor, para com os demais, o rebanho. O pastor mantém o olhar sobre cada ovelha procurando identificar as fragilidades presentes e zelar por cada uma. Ele exerce, nesse mecanismo, a função de guia, pois, além de cuidar do rebanho, o direciona a determinadas posições visando manter viva cada ovelha. Já o jogo da cidade surge com o crescimento populacional dos centros urbanos e tem por objetivo estabelecer formas coletivas de convivência. Trata-se de uma tecnologia voltada à população como um todo, pretendendo mantêla sobcontrole ao estipular modos padronizados de vida. O controle estabelecido por essa técnica não vem somente manter ou reter a população em seus domínios, mas busca também aprimorar todo o corpo social não só em fatores econômicos, mas também em questão de saúde, o que proporcionará o surgimento de alguns saberes para suprir tais necessidades: "inicialmente, a estatística, a economia e a demografia; depois a saúde pública; logo adiante, todas as áreas psi (a psiquiátrica, a psicologia, a psicanálise)" (VEIGA-NETO apud BUJES, 2002, p. 77).

Então, com a associação dessas duas técnicas, obtém-se uma forma de governo racional e inteligente, capaz de obter 
determinados resultados ao provocar determinados movimentos ou mudanças na vida social. Portanto, governo segundo Foucault (apud BUJES, 2002, p. 77) é:

[...] a maneira de dirigir a conduta dos indivíduos ou de grupos: [governamento] das crianças, das almas, das comunidades, das famílias, dos doentes. Ele não recobria apenas formas instituídas e legitimas de sujeição política ou econômica; mas modos de ação mais ou menos refletidas e calculadas, porém todos destinados a agir sobre as possibilidades de ação dos indivíduos. Governo, neste sentido, é estruturar o eventual campo de ação do outro.

Dessa forma, a governamentalidade permite ao Estado dispor corpos e os dirigir para se obter certos efeitos. Tais disposições e direcionamentos ocorrem em locais e com práticas diferentes, mas cada estrutura, como a da escola, da fábrica, do exército, etc., mantêm-se conectadas umas às outras e ao Estado, pois o efeito esperado nessas instituições é o mesmo: dirigir a vida social de cada indivíduo. Para isso, "o conjunto de práticas, de rotina e de rituais institucionais" (BUJES, 2002, p. 79) é orientado por metas determinadas segundo um processo de racionalização da população, o que torna tais atividades governamentais. Em meio a esse cenário e a essas tecnologias de poder, surge o modelo de escola atual, instituições governamentais, máquinas, gerenciando a vida de pessoas e produzindo determinadas subjetividades, objetivando um efeito: aprimorar, cuidar e controlar o corpo social em sua micro - partícula, nos gestos, hábitos e pensamentos. 


\section{A FORMULAÇÃO DO CONCEITO DE CRIANÇA E A INFLUÊNCIA DE ALGUNS PENSADORES NA CONFIGURAÇÃO DAS PRÁTICAS ESCOLARES}

A gênese da escola moderna, cujo modelo ainda se perpetua, ocorreu mediante dois fatores: primeiro, o aumento populacional urbano europeu motivado pelo desenvolvimento industrial (já citado anteriormente), proporcionando um crescimento no número de pessoas marginalizadas que se aglomeraram nas cidades, formando uma população de mendigos, constituídas por pessoas adultas acompanhadas de seus filhos e crianças órfãs; e segundo, a uma mudança na concepção de criança.

Na segunda metade do século XVI, diante do aglomerado de braços inativos que povoavam as cidades e viviam às margens dos mecanismos de produção, surgiu uma preocupação com essas pessoas como já foi demonstrado. Via-se nelas uma força produtiva desperdiçada e, nas crianças, uma possibilidade de utilização e garantia de futura mão de obra, procurava-se evitar que, quando adultas, elas se tornassem, segundo os discursos das autoridades da época, sujeitos criminosos, como podemos ver abaixo o depoimento de um rei datado de 1548 :

Em estes reinos de seis ermos a esta parte, pessoas piedosas tem dito ordem para que haja colégios de meninos e meninas, desejando dar remédio à grande perdição que de vagabundos, órfãos e crianças desamparadas havia [...] porque é certo que ao se remediar estas crianças perdidas põe-se obstáculos aos latrocínios, delitos graves, e enormes, que por se 
criarem livres e sem dono, aumentam, porque se tendo criado em liberdade de necessidade hão de ser quando grandes gente indomável, destruidora da lei pública e corrompedora dos bons costumes, contaminadora das gentes e pessoas. (VARELA apud ENGUITA, 1989, p. 109)

Constatamos, dessa forma, que havia uma preocupação por parte do governante em direcionar o desenvolvimento social de tais crianças, mantendo-as sob controle. Visando controlar tais grupos sociais, edificam-se, nesta época, os "grandes enclausuramentos", para os adultos instituiu-se o internamento em "workhouses, hópitaus, zvchthausen" (ENGUITA, 1989, p. 108) e para as crianças, os orfanatos, onde recebiam preparação disciplinar para serem introduzidas em manufaturas. A criança, qualificada como mão de obra barata e futura, despertava grande interesse nos industriais, que encomendavam grande número para serem submetidas a trabalhos em suas indústrias.

Aliado ao processo de internação das crianças e seu direcionamento para o mundo do trabalho, ocorre também na modernidade uma mudança na forma de concebê-la, o que, junto com seu enclausuramento, propiciará o surgimento da escola. A criança passa a ser percebida como um ser inacabado, carente e individualizado, reconhecendo-se a necessidade de resguardo e proteção. Portanto, esta deve ser instruída e preparada para ser integrada à sociedade devido às suas carências e, tratando-se de uma sociedade industrial, isso se concretiza ao torná-la um operário. A criança é um ser maleável que pode ser modelado e, aproveitando-se 
de sua imatura razão, constituído como o indivíduo que a sociedade necessita, um que não questione sua condição. É importante destacar que o modo como essa educação procede não se dá da mesma forma para todos, "de fato, tal como nos dias de hoje, existia então diferentes infâncias cujas formas de socialização variavam consideravelmente" (VARELA E ALVAREZ - URIA apud BUJES, 2002, p. 47).

Os modos de educação se diferenciam de acordo com a classe social que a criança ocupa, havendo três tipos de realidades para a criança segundo sua classe, a pertencente à nobreza, à burguesia e a criança pobre marginalizada. Diante dessas realidades, as formas e objetivos com os quais se devem educar as crianças serão formulados a partir de contribuições filosóficas da época. No início da modernidade, o pensamento inatista ainda perpetuava e outorgava superioridades essencialistas à nobreza que, dessa forma, justificava sua posição social. Os nobres sustentavam a ideia de que nasciam dotados de capacidades cognitivas superiores às demais classes, o que causava um descontentamento na burguesia que se fortalecia e reivindicava posição social similar à nobreza. Para isso, as ideias de Locke foram fundamentais para contestar a superioridade inata da nobreza. Locke dizia que todo o conhecimento que o indivíduo possui é captado pelos sentidos, portanto, o que constitui e qualifica o sujeito é fruto da organização de suas experiências (BUJES, 2002). Porém, o que se pretendia não era defender a igualdade de direitos da criança em geral, mas sim promover uma ruptura entre nobreza e burguesia, mostrando que estas podem ter a mesma educação e direitos, uma vez que possuem capacidades iguais. 
Locke também afirmava que a criança era dotada de uma natureza bárbara e próxima à selvageria, concluindo que esta carece de razão e por isso necessita ser instruída. Para Locke, "é preciso desviar a criança da sua natureza que a torna frágil para conduzi-la à razão" (BUJES, 2002, p. 48) e igualmente para Descartes, "as crianças não são confiáveis porque lhes falta razão - sinal de sua animalidade e selvageria - sua natureza é voltada para o prazer, o instinto, a desordem" (BUJES, 2002, p. 49). A partir desse pensamento, a criança é apresentada como possuidora de um mal natural e esta, sendo incapaz de por si só transcender a essa condição, fazse necessário intervir em suas vidas, o que, a partir de termos foucaultianos, chama-se governamentalização da infância.

Essa concepção da natureza infantil como maléfica sofre uma mudança com a publicação da obra Emílio de Rousseau em 1762. O modelo de educação apresentado nesse livro tem como base a distinção entre o homem natural (utópico) e o social, dizendo que a natureza humana não é maléfica e que esta traz algumas potencialidades que devem ser desenvolvidas. O mal, para ele, está na sociedade que pode vir a corromper o homem (BUJES, 2002). Então, sua proposta de educação visa desenvolver primeiramente tais possibilidades para depois, com o direcionamento do mestre, ser instruído na conduta social. Trata-se de um desenvolvimento pautado numa liberdade direcionada pelo mestre, pois este, tendo convivido durante determinado tempo com seu aluno, produz um saber sobre sua natureza, cabendo a ele conciliar as vontades e impulsos naturais com as leis da sociedade, para isso Rousseau diz: 
A pobre criança que não sabe nada, que não pode nada, que não conhece nada, não está à vossa mercê? [...] Sem dúvida não deve ela fazer o que quer, mas não deve querer senão o que quiser que ele faça; não deve dar um passo que não tenhas previsto; não deve abrir a boca sem que saibais o que vai dizer. (ROUSSEAU apud BUJES, 2002, p. 50).

A educação proposta por Rousseau consiste numa liberdade "bem regulada". A criança é submetida a uma autoridade cujas leis são assimiladas e internalizadas por ela, sendo estas, ditas por Rousseau no Contrato Social (1999), a vontade geral de toda a sociedade. Assim, o bom cidadão é produzido por um processo de autoformação e também automonitoramento, pois desenvolve sua própria natureza e, ao mesmo tempo, com os direcionamentos do mestre, sua vontade consiste em querer nada além das leis sociais, vivendo de acordo com elas como se fossem suas próprias aspirações. Há uma introjeção da lei no corpo do indivíduo, a lei, de origem externa, corresponde consigo mesma no corpo do indivíduo.

Kant também propõe uma educação pautada na liberdade do sujeito, uma liberdade que, segundo ele, deve ser construída:

Um dos maiores problemas da educação é o de poder conciliar a submissão ao constrangimento das leis com o exercício da liberdade. Na verdade o constrangimento é necessário! Mas de que modo cultivar a liberdade? É preciso habituar o educando a suportar que sua liberdade seja submetida ao constrangimento de outrem. [...] Sem 
essa condição [...] terminada a sua educação, não saberá usar sua liberdade. (KANT apud BUJES, 2002, p. 52)

Portanto, a proposta de Kant, concordando com Rousseau, é pautada no desenvolvimento de uma liberdade de ação administrada pelo acatamento das leis, esse processo Foucault chama de "incorporação do soberano" (BUJES, 2002, p. 52). Não se trata, portanto, de uma liberdade inata, mas sim de uma liberdade construída em que a repressão pela lei esteja na própria racionalidade do indivíduo.

[...] nas ideias de Kant e Rousseau - como de resto, em todas as análises sobre a educação - está presente uma concepção de sujeito: um sujeito único e singular, que está no centro dos processos sociais, alguém que vai atingir a maioridade através da razão, mas que necessita de educação para que tal processo se dê na direção desejada de sua inteira destinação [...]. (BUJES, 2002, pág. 54)

Como demonstrado, a concepção de criança e como educá-la é preocupação de vários pensadores da modernidade, dentre os quais citamos Locke, Descartes, Rousseau e Kant. A partir dessa ligeira exposição, pudemos ver que estes pensadores defendiam a ideia de que a criança, por carecer de instrução, deve ser educada. Seu processo de amadurecimento deve ser outorgado a outrem que, sendo o portador do saber, proporcionará o cultivo de algumas características e comportamentos referentes aos valores da época. Portanto, o projeto de educação que se constrói na modernidade é um projeto civilizador, consiste em 
estabelecer e determinar normas de conduta tornando-as naturais mediante um processo de acatamento e submissão às mesmas. Aliado a essa mentalidade, para alcançar estes fins, surgem na modernidade técnicas de educar, ou, em outras palavras, técnicas de submissão à lei e a ordem, que terão como alvo a criança. Tais tecnologias compõem o que Foucault chama de disciplina.

\section{O CORPO COMO ALVO DO PODER E A PRODUÇÃO DE CORPOS DÓCEIS}

Como dissemos, a máquina abstrata é causa imanente de certas relações de poder, ou seja, atua simultaneamente ao seu efeito e tem como alvo o corpo do individuo. É na relação entre indivíduos, e por meio destes, que proporciona determinados modos de ação produzindo realidades, efetuando-se e atualizando-se nestes. Portanto, o corpo é o alvo do poder e também portador deste enquanto realidade virtual. O poder provoca, ao passar pelos corpos "imersos em suas redes" (VEIGA-NETO, 2004, p. 74), transformações nos mesmos.

De uma maneira simplificada, ele se manifesta como um agente (uma ação) capaz (que tem capacidade) de alterar o estado de um corpo. Pode - se entender tal capacidade como um poder de força, de modo que faz sentido chamarmos de poder a uma ação que se exerça sobre o estado de um corpo. É isso que Foucault entende por poder: uma ação sobre ações. (VEIGANETO, 2004, p. 74) 
Dessa forma, o exercício do poder consiste em uma ação capaz de comandar outras ações, de governá-las moldando certo tipo de indivíduo. O poder possui uma "positividade" (MACHADO, 1988), pois, ao afetar os corpos modificandoos e os moldando física e subjetivamente, sempre tem consigo uma carga de objetivos. Seguem em seus fluxos determinados direcionamentos que reorientam aqueles que sofrem seu efeito. A carga de interesses políticos agregados a esse fluxo visa não à aniquilação do corpo e da subjetividade e nem ao afastamento da vida social, impedindo a atividade do indivíduo, mas sim

gerir a vida dos homens, controlá-los em suas ações para que seja possível e viável utilizá-los ao máximo, aproveitando suas potencialidades e utilizando um sistema de aperfeiçoamento gradual e contínuo de suas capacidades. Objetivo ao mesmo tempo econômico e político: aumento do efeito de seu trabalho, isto é, tornar os homens força de trabalho dando-lhes uma utilidade econômica máxima; diminuição de sua capacidade de revolta, de resistência, de luta, de insurreição contra as ordens do poder, neutralização do efeito de contra - poder, isto é, tornar os homens dóceis politicamente (MACHADO, 1988, p. 193).

O corpo dos indivíduos assim é representado conceitualmente, corpo maleável passível de dominação e utilização, corpo produtivo e, se bem governado, fonte de riquezas. Essa é a visão moderna sobre o homem comum, o homem das multidões e das massas descoberto ao se individualizar cada célula do corpo social. Tal 
representação é fruto do pensamento moderno. Vejamos então como tal conceito de corpo se configurou.

Foucault fala que a descoberta do corpo como objeto maleável e manipulável, "objeto alvo de poder" (FOUCAULT, 2007, p. 117), ocorreu devido a dois fatores: primeiro ao pensamento cartesiano, pois, a partir de Descartes, o corpo humano é concebido como composto orgânico formado por várias estruturas que funcionam interconectadas, como aparelhos mecânicos; em segundo lugar, devido às instituições como o exército e a escola. Nessas instituições, o corpo é visto como passível de controle, ou seja, as operações integrantes do campo de possibilidades do corpo podem ser submetidas a uma ordem, descobrindo, dessa forma, o caráter de utilidade do corpo. Portanto, o corpo torna-se um objeto analisável e também manipulável, pois é submetido a um controle que o insere em uma função de utilidade, trata-se de um composto orgânico maleável, passível de ser moldado, "é dócil um corpo que pode ser submetido, que pode ser utilizado, que pode ser transformado e aperfeiçoado" (FOUCAULT, 2007, p. 118). Em relação ao efeito e produto do poder, podemos dizer que este, ao atuar no corpo, o torna útil e obediente. A esta modalidade do poder Foucault chama de "poder disciplinar" (FOUCAULT, 2007, p. 119).

O poder disciplinar tornou-se questão para Foucault no momento em que percebe, ao desenvolver uma analítica da história das penalidades jurídicas, que com o surgimento das prisões aparecem mecanismos que permitem um controle quase total dos prisioneiros (MACHADO, 1988). Ele observa também que tais mecanismos de controle 
estão presentes em outros espaços institucionais, como por exemplo, a escola, os quartéis, as fábricas, os hospitais, etc. Em sua analítica, ele descreve o poder disciplinar como um composto de técnicas que se originaram em locais diversos, não se trata de uma "descoberta súbita" (FOUCAULT, 2007, pág. 119), mas sim de um composto de tecnologias mínimas de poder que, com o decorrer de acontecimentos históricos, foram se perpetuando, aperfeiçoando e sendo reunidas em espaços comuns.

A disciplina é um conjunto de técnicas que, além de manter um controle sobre determinado grupo de pessoas, também atua sobre o corpo e a subjetividade de cada indivíduo. É esta técnica que proporciona fabricar "corpos submissos e exercitados, corpos dóceis" (FOUCAULT, 2007, p. 119). Trata-se de uma grande descoberta para a modernidade, pois, com a crescente população e também a necessidade de força de trabalho para as fábricas, proporciona um processo de adequação população - trabalho. Por meio da disciplina se organiza a massa desordenada de pessoas e os individualizam, governamentalizando e direcionandoos. Nas escolas capturam-se as crianças, nos hospitais os doentes, nas fábricas os adultos e nos quartéis os militares, o Estado moderno funciona disciplinarmente, composto de vários mecanismos disciplinares interligados, trata-se de uma tecnologia eficaz que proporciona intensificar os meios de produção de forma pouco custosa.

O poder disciplinar, dessa forma, "funciona como uma rede que os atravessa (aparelhos, instituições, corpos ${ }^{4}$ ) sem se limitar a suas fronteiras" (MACHADO, 1988, p. 194), reúne “[...] métodos que permitem o controle minucioso 
das operações do corpo, que asseguram a sujeição constante de suas forças e lhes impõem uma relação de docilidade — utilidade [...]" (FOUCAULT apud MACHADO, 1988, p. 194). A disciplina proporciona a utilização racional e política do corpo. Com seus mecanismos, ao esculpir o homem moderno, assim como uma técnica artística de talhar pedras e dela extrair um corpo antes representado segundo a vontade do artista, calculado no detalhe, atuando no mais minucioso elemento do corpo humano, govenamentalizando os pequenos gestos e as pequenas posturas.

\section{CONCLUSÃO}

A partir das investigações realizadas, podemos afirmar que a escola é uma máquina cujo funcionamento se dá pelo movimento das engrenagens mediadas por relações de poder disciplinar efetuadas segundo um diagrama. O diagrama, como vimos, consiste em discursos normativos que atribuem determinadas funcionalidades aos elementos do dispositivo (ou agenciamento), dessa forma, a escola compreendida como um agenciamento está interligada com a governamentalidade estatal, pois esta lança mão dos diversos dispositivos como táticas civilizatórias. Queremos dizer que o Estado, ao regulamentar o funcionamento do dispositivo escolar, tem por objetivo a formação de indivíduos segundo um modelo pré-estabelecido, uma normatividade.

Portanto, toda a pedagogia implantada nas escolas tem, como pano de fundo, uma funcionalidade que visa certos objetivos políticos. Atrelado aos discursos pedagógicos, os 
regulamentos escolares delimitam as funções que o professor deverá cumprir para que o objetivo final seja alcançado, portanto, atualiza sobre este, como exemplo, uma função qualificada descrita no diagrama. Sua função está localizada estruturalmente de maneira tática em que este tenha sua liberdade de ensino direcionada e governamentalizada, cumprind o o papel de direcionar a ação dos alunos. O professor é a "mão de longo alcance" do Estado que governa os gestos e as atitudes dos alunos, construindo sua subjetividade.

A máquina abstrata comporta, em seu corpus discursivo, o "entendimento" da "condição natural" e da "ideal" da criança interpondo estre essas polaridades, estratégias que transformem uma na outra. A máquina apresenta, como formação discursiva historicamente construída, o conceito de criança como um ser em formação que por si só é incapaz de maturação, logo é necessário um cuidado e um zelo para direcioná-la a um ideal esperado, que Foucault caracteriza como indivíduo normalizado ou corpo dócil. Percebemos que nessa linha traçada de uma compreensão a outra, a criança tem a normalidade apenas como potencialidade, portanto, suas características que a aproximam da "selvageria", como diria Descartes, devem ser neutralizadas, pois não corresponde com a normalidade de um cidadão civilizado.

Retomamos então a questão que propomos em nosso objetivo para melhor compreendê-la: qual o papel da escola na sociedade segundo o que apresentamos por meio de Deleuze e Foucault? Esses filósofos nos permitem pensar a escola inserida em um projeto maior de civilização ou socialização dos sujeitos, pois o Estado visa um modelo de indivíduo que produza riquezas e não questione sua situação social ou, até 
mesmo, que defenda a situação estratégica que estrutura a sociedade. Como isso é possível? Por meio de diversos agenciamentos que atualizam, nos corpos, esse modelo de indivíduo por meio de relações de poder e a escola atualiza, como um desses agenciamentos, não só a norma cidadã, mas também um conjunto de regulamentos e práticas pedagógicas que solicita a cada indivíduo mover-se de acordo com as demais engrenagens, contribuindo com o funcionamento da máquina como um todo. Assim a criança saberá, ao ter sido "formada" pela escola, mover-se da maneira esperada em qualquer espaço da sociedade.

\section{NOTAS}

${ }^{1}$ Mestre em Filosofia - PPGFIL UFES. E-mail: brunoabiliogalvao@hotmail. com

${ }^{2}$ Advertência: embora este artigo publicado na obra Lei, Segurança e Disciplina ocupe as páginas 71-109, a versão online deste artigo não segue a numeração e nem a mesma quantidade de páginas do original, portanto, como tivemos acesso à versão online e esta cita a referência original, optamos por seguila, porém a numeração das páginas, por estar discordante, optamos pela do arquivo online ao qual tivemos acesso.

${ }^{3} \mathrm{~A}$ população pobre, além de carecer de cuidados, também carregava uma carga de preconceitos morais. Cf. ENGUITA, 1989.

${ }^{4}$ Parênteses nosso. 


\section{REFERÊNCIAS}

BUJES. M. I. E. Infância e maquinarias. Rio de Janeiro: DP\&A, 2002.

DELEUZE, G. Foucault. São Paulo: Brasiliense, 2005.

ENGUITA. M. F. A face oculta da escola: educação e trabalho no capitalismo. Porto Alegre: Artes Médicas, 1989.

FOUCAULT, M. Vigiar e Punir. Rio de Janeiro: Vozes, 2007.

FOUCAULT, M. Microfísica do Poder. Rio de Janeiro: Graal, 2010.

MACHADO, R. Ciência e Saber: A Trajetória da Arqueologia de Michel Foucault. Rio de Janeiro: Graal, 1988.

NABAIS, C. P. A Dobra Deleuze - Foucault. In: CASCAIS, A. F.; LEME, J. L. C. e NABAIS, N. (Eds.). Lei, Segurança e Disciplina: trinta anos depois de Vigiar e Punir de Michel Foucault. Lisboa: CFCUL, 2009, p. 71-109. Disponível em: http://cfcul.fc.ul.pt/biblioteca/online/pdf/catarinanabais/ adobradeleuzefoucault.pdf Acesso em: 16/08/214.

ROUSSEAU. Jean Jacques. O contrato social: princípios do direito político. São Paulo: Martins Fontes, 1999.

VEIGA-NETO, A. Foucault e a educação. $2^{\text {a }}$ Ed. Belo Horizonte: Autêntica, 2004. 
FOUCAULT, DELEUZE E A MÁQUINA ESCOLAR: A ESCOLA COMO...

ZOURABICHVILI. F. O Vocabulário de Deleuze. Rio de Janeiro:

Relume Dumará, 2004. 